\title{
Addressing the Prevention of Internal Displacement: the Right Not to Be Arbitrarily Displaced
}

\author{
Naziye Dirikgil ${ }^{1}[$
}

Accepted: 15 January 2022 / Published online: 31 January 2022

(c) The Author(s) 2022

\begin{abstract}
Internally displaced persons (IDPs) constitute one of the important subjects to consider for enhancing the understanding of migration. They also play a significant role to the contribution of maintenance and promotion of international peace and security and they should be an important component of any comprehensive strategy to resolve conflict and build peace. Even though IDP numbers still increase dramatically, the root causes of internal displacement have not been studied extensively. This article addresses this gap through an examination of the right not to be arbitrarily displaced and its evolution at the national level. The article first examines the content of the right not to be arbitrarily displaced and the meaning of the term 'arbitrary' in different situations of internal displacement and then demonstrates that the capacity of this right to perform a critical role for IDP protection has been facilitated by developments across national laws. The empirical analysis shows that certain countries have developed more ambitious and comprehensive national legal frameworks on IDP rights, and this process has led to the recognition of the right not to be arbitrarily displaced in their domestic frameworks. It can be argued that there are now a critical number of countries that explicitly recognise this right, and which have even created policy-making frameworks that promote the applicability of this right.
\end{abstract}

Keywords Internal displacement - IDPs · Right not to be arbitrarily displaced . Arbitrary displacement $\cdot$ National IDP laws

Naziye Dirikgil

nad11@aber.ac.uk

1 Department of Law and Criminology, Penglais Campus, Hugh Owen Building, Aberystwyth University, AberystwythWales SY23 3DY, Ceredigion, UK 


\section{Introduction}

The global crisis of internal displacement has emerged as one of the great human tragedies of our time and as a challenging issue on the international agenda. Increasing numbers of internally displaced persons (IDPs) have been forced from their homes by armed conflicts, systematic violations of human rights, natural disasters or other traumatic events. Accounting for all such factors, the Guiding Principles on Internal Displacement (GPID) define IDPs as 'persons or groups of persons who have been forced or obliged to flee or to leave their homes or places of habitual residence, in particular as a result of or in order to avoid the effects of armed conflict, situations of generalised violence, violations of human rights or natural or human-made disasters and who have not crossed an internationally recognised State border' (GPID 1998). The plight of IDPs poses a challenge of humanitarian, political and legal dimensions that also affects the international migration strategies of states and international organisations. In some cases, the degree of displacement may be so high that one can speak of whole societies becoming displaced. When a country falls into the disarray of displacement, neighbouring countries are affected too, and violence and instability often spread throughout entire regions (Cohen and Deng 1998). Internal displacement can constitute a threat to international peace and security, as has been recognised by the United Nations (UN) Security Council (United Nations Security Council. 2020). Therefore, these circumstances call for regional and international responses, not only because of humanitarian and human rights concerns but also because of collective interest in regional stability, as well as global peace and security. In this respect, IDPs constitute one of the important subjects to consider for enhancing the understanding of migration. The UNSC also confirms that IDPs play a significant role to the contribution of maintenance and promotion of international peace and security, and they should be an important component of any comprehensive strategy to resolve conflict and build peace (United Nations Security Council. 2020). Since IDPs are potential refugees, the process of addressing IDP-related issues can contribute to policy development on refugees and international migration in general. The UN 2030 Agenda for Sustainable Development, which seeks to strengthen the common commitment of universal peace and security, explicitly states that internal displacement is one of the immense challenges to sustainable development in our world today (United Nations General Assembly.(2015). Transforming our world: The 2030 agenda for sustainable development.A/RES/70/1. 2015). IDPs are often among the most vulnerable populations, as evident in today's high-profile IDP crises. Today, there are approximately 50.8 million IDPs due to violent conflict and human rights violations, including major cases like Iraq, Sudan, Syria and Democratic Republic of Congo, and natural disasters, such as earthquakes in Haiti, floods in Fiji and Gambia, and tropical storms in Sri Lanka (IDMC. 2020).

Despite the substantial body of academic literature on humanitarian assistance to IDPs, and the applicability of different human rights, less attention is given to the prevention of internal displacement. This is evident since the launch of the 
GPID in 1998. Studies heavily focus either on displacement after conflict, excluding other causes of displacement such as natural disasters and development projects, or on specific rights of IDPs such as humanitarian assistance, the right to return and resettlement. The root causes of displacement that impact IDPs in the first place, and are therefore critical for the prevention of internal displacement, are not covered and are considered an area for further study. Ferris (2008, p. 11) argues that the extent to which the GPID have prevented arbitrary displacement is less clear and points out that this uncertainty is challenging for ensuring IDPs' basic human rights. A limited number of studies address the prohibition of forced displacement in general and they are not IDP-focused, but are somehow relevant to the prevention of internal displacement as they cover some key aspects. These include the existing responses of international law to the various causes of displacement, identifying the human rights that displacement violates (Stavropoulou. 1994), contributing to the general debate on the emergence of the human right not to be displaced (Morel. 2014), examining the prohibition of forced displacement in times of war (Jacques. 2012), and examining an individual right to be protected from forced displacement that results from armed conflict (Proukaki. 2018). While all these studies enable one to draw valuable conclusions with regard to the state and applicability of International Humanitarian Law (IHL) and International Human Rights Law (IHRL) in cases of prevention of forced displacement, more research is needed to examine how principles of international law translate into concrete actions in the prevention of internal displacement.

This paper addresses this gap by contributing to the analysis of the pre-displacement phase, which still remains under-theorised in existing IDP studies. IDP-related issues are dealt with either along with refugees, or else with other categories of protected persons. Internal displacement often becomes a subject of research interest after displacement takes place; therefore, analyses of state responsibilities and policies for the prevention of and early responses to the causes of displacement are still lacking in the literature. This article argues that one way of conducting such analysis is to focus at the national level. Scholars who address the domestication of the GPID have noted how national laws and policies on internal displacement have evolved and expanded, with discussions on the benefits and shortcomings of different models with reference to specific cases. Such works offer valuable insights into the issues surrounding displacement and the need for enhanced protection, even though they do not comprehensively address national laws and policies on the prevention of internal displacement. This issue has been highlighted in the Special Representative of the Secretary-General's Report that was presented to the UN General Assembly and which stated the need for a bottom-up approach to convincing states affected by internal displacement to incorporate the GPID into domestic law (United Nations General Assembly. 2010).

This paper aims to examine how IDPs' protection from arbitrary displacement has evolved at the national level. It first provides an overview on how the GPID dealt with the prevention of arbitrary displacement. It then examines the content of the right not to be arbitrarily displaced and the meaning of the term 'arbitrary' in 
different situations of internal displacement. To further understand how exactly the prevention of arbitrary displacement is recognised at the national level, the paper then conducts an analysis of national IDP frameworks. For this analysis, a total number of 448 instruments, ${ }^{1}$ including national laws, policies and on-going normative developments, are examined to show the different approaches taken by the states while promoting the recognition of the right not to be arbitrarily displaced in their national IDP frameworks. Finally, the consequences of internal displacement and their impacts on the lives of IDPs, their hosts and the communities they leave behind are examined.

\section{Re-assessing the Prevention of Displacement}

\section{Historical Background of Internal Displacement}

While displacement has always existed across the globe, encompassing different forms of forced movement of people, internal displacement only emerges during the second half of the twentieth century. Internal displacement is often associated with the category of IDPs, which can be identified as far back as the Second World War. From the Second World War onward, an initial identification of the category of IDPs is used occasionally to differentiate people who are displaced within their own countries from other categories of displaced people at the international level (Orchard. 2019). The term IDPs was not used explicitly back then but instead, references were made to people who are displaced but confined within state borders (Phuong. 2005). The category becomes more prominent in the 1970s, as the United Nations General Assembly (UNGA) and the Secretary-General began to call on the United Nations High Commissioner for Refugees (UNHCR) to assist specific groups that were referred to as 'displaced persons' but who in practice were often displaced within their own countries (Orchard. 2019, p. 2; Cohen. 2006). These practices contributed to creating a shared understanding at the international level held by UN agencies, the International Committee of the Red Cross (ICRC) and states that IDPs should receive international assistance and protection. However, there was no consensus that IDPs represented an international problem until the 1990s.

The need for international standards for the protection of IDPs became apparent in the 1990s when the number of people uprooted within their own countries by armed conflict, internal strife, natural disasters and human rights abuses began to soar (Kälin. 2005). The internal displacement issue also became more prominent because of the realisation that if left unaddressed, internal displacement would not only cause internal instability but also spill across borders and threaten regional stability (Annan, 1998). In 1992, the international community's recognition of the magnitude of the crisis and the urgent need for action led the Secretary-General of the UN to appoint a representative on IDPs in order to evaluate existing legal

\footnotetext{
1 The number of IDP-specific documents (448) represents all instruments that have been developed in all regions between 1998 and 2020.
} 
protections and institutional machinery for IDPs. Since then, the issue of internal displacement was placed on the international agenda and was recognised as a legitimate matter of international concern. This momentum culminated with the initiative for the drafting process of the GPID which are considered a milestone in the process of establishing a normative framework for the protection of IDPs (IDMC. 2021). From then on, states, the UN and other international organisations and NGOs made a range of commitments to address the problem of internal displacement in order to take effective measures to provide protection and assistance to IDPs, and to reduce the number of IDPs (United Nations General Assembly. 2015).

Within this broader context of the historical development of internal displacement, it is also possible to identify the more specific focus regarding the prevention of internal displacement. When the concept of 'prevention of forced displacement' surfaced with the refugee flows of the 1980s, the perceived threat posed by these flows to national, regional and international security was mainly intended to be addressed from a refugee protection perspective rather than addressing the needs of displaced people before becoming refugees. Even though a clear link between violations of human rights and the flight of displaced people was made back in the 1980s (UNGA. 1981), the human rights approach to the prevention of forced displacement gained influence in the 1990s, which also contributed to a new perspective of state policies. As stated by Senior Protection Officer of the UNHCR, '[t]he $90 \mathrm{~s}$ were to witness a dramatic change in the way international relations affected humanitarian policies, of which the expansion of the concept of prevention was one of its main manifestations' (Zapater. 2010, p. 5). In this respect, the adoption of the GPID in 1998 was a critical turning point in how the prevention of internal displacement was framed and expanded.

\section{The Aspect of Prevention of Internal Displacement}

In the context of IDP protection, 'prevention of internal displacement' may refer to two fundamental steps that states can take to exercise their responsibility with regard to internal displacement. The first step is the prevention of the root causes of forced internal displacement or the prevention of people from getting exposed to situations that can be considered as causing a risk of displacement, and where some kind of violations of rights or harm to civilians is not already happening. The second step is about when displacement is unavoidable, and that is aiming at taking steps in advance to mitigate its harmful effects. Thus, the prevention of acts that lead to displacement is not only focused on measures to distil what must be done before displacement occurs but also minimise forced displacement and mitigate its adverse effects when displacement becomes the only option. These efforts should not be perceived as the restriction of freedom of movement, impeding people's ability to move, or influencing their decision to do so (Global Protection Cluster Working Group, 2007). Otherwise, strictly limiting the content of prevention of internal displacement merely to the foreseeable displacement before this displacement happens would not be feasible or practical. 
The prevention of displacement can cover the prohibition of forced displacement as well as what may be the exceptions to this prohibition, including the conditions under which legal displacement can be carried out to promote respect for the right not to be arbitrarily displaced. Section II of the GPID, comprising Principles 5 through 9, reflects how the prevention of internal displacement should be understood within the context of IDP's right to be protected from arbitrary displacement. These principles relating to protection from displacement contain a range of state obligations on the prevention of internal displacement, such as full respect for international law, and in particular human rights and humanitarian law (Principle 5), taking positive steps to mitigate the vulnerability of particular populations (children, women or elderly) to displacement (Principle 7), and protection of fundamental human rights such as right to life, dignity, liberty and security of those displaced in situations where displacement is absolutely necessary (Principle 8). These principles entail the substantive guarantees to ensure respect for any human right. In other words, respect for the right to life or right to dignity, the protection of vulnerable populations, and respect for IHRL and IHL are the most fundamental guarantees to the enjoyment of human rights or to the protection of civilians (Kälin \& Künzli. 2010). If these substantive guarantees are not violated, it is possible to attain a higher level of reinforcement of protection from internal displacement. In this sense, Principles 5, 7 and 8 underlie the interdependency of human rights and clearly demonstrate that the right not to be arbitrarily displaced cannot be adequately protected if substantive rights are not guaranteed. These substantive guarantees within the principles relate to protection from displacement in order to strengthen the protection of the right not to be arbitrarily displaced. The legal foundation of these principles is well established and the rights they include are explicitly recognised under international law. In the same vein, Principle 9, which provides the right of indigenous people to protection from displacement and therefore highlights the state obligation to protect against the displacement of indigenous people, can also be explicitly found in instruments on the rights of indigenous peoples (Indigenous and Tribal Peoples Convention No. 169. 1989). However, compared with the other principles regarding protection from displacement, Principle 6 contains an innovative right called the right to be protected against being arbitrarily displaced from his or her home or place of habitual resident'. The reasons why this is an innovative right can be explained as follows.

The GPID are grounded in existing human rights and humanitarian law standards, reflect existing rules and clarify how they apply to internal displacement settings instead of creating new obligations. In order to clarify the content and the applicability of each principle to situations of internal displacement, it is possible to cite a multitude of existing legal provisions for almost every principle (Kälin, 2001). For instance, the legal basis for Principle 1, which deals with IDPs' protection from discrimination, can be explicitly found in many existing human rights and humanitarian law provisions (Kälin, 2008a). Guarantees regarding the principle of nondiscrimination are clear, and as a civilian, an IDP's right to be protected against discrimination is very well grounded in international law. Therefore, in IDP cases where the principle of non-discrimination is concerned, it is not questioned whether this principle exists, but how it can be better provided to those in need. 
However, some rights included in the GPID do not reflect this explicit legal basis. The language is used in a more general sense in the existing treaty law when we consider the content of some principles. Principle 6 on 'the right not to be arbitrarily displaced' is a good example of this condition. No existing instrument mentions such a right explicitly. However, IHL prohibits forced displacement in armed conflict situations, and IHRL guarantees not only freedom of movement but also the right to choose one's own residence. Therefore, protection against arbitrary acts of displacement can only be deduced from the relevant provisions of international law. The contribution of Principle 6 is to mention this right explicitly for the first time. 'The purpose of expressly stating a right not to be arbitrarily displaced was to defin[e] explicitly what is now only implicit in international law' (Kälin, 2008b). Principle 6 also contributes to adequate and comprehensive coverage of all instances of arbitrary displacement since other movement-related rights do not spell out all the circumstances under which displacement is permissible. In the light of this information, Principle 6 states that:

1. Every human being shall have the right to be protected against being arbitrarily displaced from his or her home or place of habitual residence.

2. The prohibition of arbitrary displacement includes displacement:

3. When it is based on policies of apartheid, ethnic cleansing or similar practices aimed at/or resulting in altering the ethnic, religious or racial composition of the affected population;

4. In situations of armed conflict, unless the security of the civilians involved or imperative military reasons so demand;

5. In cases of large-scale development projects, which are not justified by compelling and overriding public interests;

6. In cases of disasters, unless the safety and health of those affected requires their evacuation; and

7. When it is used as a collective punishment.

8. Displacement shall last no longer than required by the circumstances (GPID, 1998).

Paragraph 1 clearly reflects the IHRL perspective while paragraph 2 reflects IHRL and IHL provisions, depending on what kind of cases lead to displacement of people. The explicit recognition of the right not to be arbitrarily displaced is a positive step for states, especially those with high numbers of IDPs, as it ensures that individuals and groups are not subjected to involuntary displacement except when absolutely necessary, and that in such cases, displacement is not carried out in an arbitrary manner and in violation of international law. Promoting the explicit recognition of this right in the GPID is essential for raising awareness of the need for IDP protection from arbitrary displacement and, therefore, their specific protection needs. Overall, Principle 6 of the GPID serves as the basis for the provisions of legal instruments that are specifically dealing with the prohibition of arbitrary 
displacement. $^{2}$ The next section examines the content of the right not to be arbitrarily displaced and the meaning of the term 'arbitrary'.

\section{The Right Not to Be Arbitrarily Displaced}

Following the discussion above regarding the prevention of internal displacement and the critical role of the right not to be arbitrarily displaced in this area, the discussion now turns to examining what constitutes arbitrary acts of displacement within the content of the GPID. While Principle 6(1) of the GPID strictly prohibits arbitrary displacement, the following paragraph (2) lists a series of circumstances as not constituting arbitrary displacement. Principle 6(2) includes five different categories of internal displacement. ${ }^{3}$ Two categories, which are (i) policies of apartheid, ethnic cleansing or similar practices and (ii) collective punishment, are not covered by an exception, and any interference with the right automatically constitutes a human rights violation ${ }^{4}$ because in most cases of forced internal displacement, such categories were not a by-product of criminal activity or conflict but a deliberate policy (Gelazis. 2005; Forced Migration Review. 2015). However, the right not to be arbitrarily displaced is not an absolute right in three categories: (i) cases of armed conflict, (ii) natural disasters and (iii) development projects. It includes limitation clauses that allow for state interference under certain conditions. Therefore, the term 'arbitrary' provides the conditions under which displacement can be carried out without violating international law, thus without being arbitrary (Adeola. 2016). If displacement is permissible, it is important to determine whether state acts are legally justified. If the conditions for lawful limitations of a right cannot be found, then these acts are deemed arbitrary. ${ }^{5}$ In this sense, the right not to be arbitrarily displaced provides conditions of displacement (the requirement of compliance with international law), and also the minimum procedural standard to determine the arbitrariness of the displacement (GPID 1998). The three categories of armed conflict, natural disasters and development projects can now be examined in detail.

\footnotetext{
${ }^{2}$ In addition to the GPID, there are 5 instruments explicitly include right not to be arbitrarily displaced. These are Kampala Convention, Great Lakes Protocol on IDPs, Pinheiro Principles, London Declaration on IDPs and ILO Convention No. 169. However, Pinheiro Principles and ILO Convention No. 169 are not specifically designed for the protection of IDP rights but to some extent covers IDP's protection from arbitrary displacement.

3 The five categories are a non-exhaustive list of cases to decide whether displacement is arbitrary, which can be expanded with new causes of internal displacement, such as harmful practices that may constitute, according to the Kampala Convention Article 4(e), sufficient reason to displace people and are therefore considered to amount to arbitrary displacement.

${ }^{4}$ For instance, according to Article 7 of the Rome Statute of the International Criminal Court (ICC) and Article 2 of the International Convention on the Suppression and Punishment of the Crime of Apartheid, when apartheid, ethnic cleansing and collective punishment cause displacement, these acts are considered arbitrary in any ground as they are absolutely prohibited under international law.

5 Kälin and Künzli provided a detailed checklist of the constitutive elements of a human rights violation. The limitations on right not to be arbitrarily displaced have been considered according to this checklist.
} 
In situations of armed conflict, displacement will be considered non-arbitrary where it is premised on the need to protect the civilian population or for the realisation of certain military exigencies. Otherwise, as stated in Principle 6(2) of the GPID, the displacement of populations during armed conflict is considered arbitrary unless it is justified by the security of the civilians involved or imperative military reasons. A number of sources before and after the adoption of Principle 6 demonstrate the conditions under which displacement is permissible. Prior to the GPID adoption in 1998, Article 17(1) of the Protocol Relating to the Protection of Victims of Non-International Armed Conflicts (Protection of Victims of Non-International Armed Conflicts (Protocol II). 1977) stated that if displacement has to be carried out, the provision of minimum necessities such as shelter, hygiene, health, safety and nutrition should be included in the acts of displacement. From that point onwards, the elements of necessity and proportionality become significant. In 1998, Principle 7(1) of the GPID provided insight into these elements. According to Principle 7(1), in order to meet the requirements of proportionality and necessity to justify interference with the right not to be arbitrarily displaced, states have an obligation to take all feasible alternatives, and displacement must be unavoidable and the only option available. This clause implies the criterion of necessity, or else it can be read as meaning that displacement of population is necessary, and that without it, the population will be in a serious danger. The requirement of proportionality is also given in GPID Principle 7(2), which states that when there are no alternatives, states have the obligation to ensure that such displacements are effected in satisfactory conditions of safety, nutrition, health and hygiene, and that members of the same family are not separated. After the adoption of GPID in 1998, the Human Rights Committee (HRC) also dealt with the possibility of permissible grounds of displacement, which require proportionality and necessity (1999, para. 16). These are imperative to preventing IDPs from being a pretext for illegitimate aims, such as using IDPs as human shields or using displacement as a tool of war to punish IDPs, that belongs to the same ethnic group as the enemy. Moreover, the HRC treats as arbitrary an interference with a right if it is not proportionate to the circumstances. Displacement must be proportionate in the light of its invoked purpose (HRC. 1999, para. 14), ${ }^{6}$ meaning that the state must strike a fair balance between the private interest not to be arbitrarily displaced and any other interest to be protected (Morel. 2014). Thus, the meaning of arbitrariness is interpreted broadly by the HRC not only as unlawful or against the law, but also as unreasonable ${ }^{7}$ or disproportionate in the circumstances of any given case (Joseph \& Castan, 2013). More recently, preliminary examinations and investigations of the ICC, especially since the beginning of the 2000s, contributed to this process. Such examinations reveal that most cases decided by the ICC contain the crime of forcible transfer ${ }^{8}$ of populations under the category

\footnotetext{
${ }^{6}$ HRC General Comment 27, para. 14 states that 'restrictive measures must conform to the principle of proportionality; they must be appropriate to achieve their protective function'.

7 According to the HRC, the requirement of reasonableness implies that the interference with a right must be proportional to the end sought and be necessary in the circumstances of any given case.

${ }^{8}$ In Prosecutor $v$ Stakić case, the forcible transfer of population has been defined by the International
} 
of crimes against humanity and if the restrictions are introduced, this must be based on clear legal grounds. ${ }^{9}$ Since the movements of people in the context of conflict most often constitute arbitrary displacement, when any party to an armed conflict raises military or security necessity as reasons for the displacement, close scrutiny of the motives and objectives of this act is necessary.

The second category concerns situations of natural disasters. For such situations, according to the GPID Principle 6(2)(d), displacement is permissible if the safety and health of those affected require their evacuation and is therefore non-arbitrary. Legal texts since the GPID adoption have followed this rationale. In the Budayeva and Others v Russia case (European Court of Human Rights, 2008), threats to human rights due to natural disasters lay behind the positive obligation of states to take appropriate steps to safeguard the lives of those within their jurisdiction. In this respect, states have a duty to take practical measures to ensure the effective protection of citizens whose lives might be endangered by the natural disaster risk (European Court of Human Rights. 2008, para. 132). Also, Article 4(4)(f) of the 2009 Kampala Convention stated that displacement is arbitrary if it is not justified by reasons of the safety and health of those affected. Furthermore, Article 12(3) of the Kampala Convention states that not only are states required to take steps to prevent the consequences of disasters, but they are also required to make reparation to IDPs in the event of natural disasters. Finally, the Kampala Convention establishes disaster risk reduction strategies and disaster preparedness mechanisms for the prevention of arbitrary displacement, and in this respect addresses a gap in the GPID which had not provided disaster risk reduction strategies.

Finally, the third category covers situations of large-scale development projects, where displacement is considered non-arbitrary if it is for compelling and overriding public interests. While the GPID is not clear on whether there is some specific magnitude of public interest that is necessary and sufficient to permit displacement, states have an obligation to consider the requirement of proportionality and necessity prior to any decision requiring displacement. These are the minimum procedural requirements highlighted in the GPID Principle 7(1): "prior to any decision requiring the displacement of persons, the authorities concerned shall ensure that all feasible alternatives are explored in order to avoid displacement altogether'. However, where alternatives to displacement are not feasible, states need to consider the strategy for minimising displacement and avoiding the adverse effect of displacement (Adeola. 2016). Therefore, if displacement is unavoidable, states need to ensure the right of IDPs to receive protection and humanitarian aid, protection from acts of torture and discrimination, and provision of basic social amenities such as security, health care and shelter. After displacement, the state needs to ensure the right to effective remedies. After the adoption of the GPID in 1998, additional criteria for a response tailored to developmentinduced displacement are included in Article 5 of 2006 Great Lakes Protocol. These

\footnotetext{
Footnote 8 (continued)

Criminal Tribunal for the Former Yugoslavia as 'the forcible displacement of persons which may take place within national boundaries'.

9 For instance, the Prosecutor of the ICC charged Omar Al Bashir with forcefully transferring people without any legal justification. Moreover, the Prosecutor issued a press release acknowledging that alleged crimes including forced displacement were reported since the 1990s in the DRC.
} 
are the following: (i) prior to displacement, IDPs are to be fully informed of the reasons and procedures concerning development-induced displacement, and (ii) the consent of the IDPs must be obtained. All these elements provide grounds to decide whether there is a substantive and sufficient justification for a deprivation of a right.

\section{The Prevention of Arbitrary Displacement Across National IDP Instruments}

After examining the content of the right not to be arbitrarily displaced and state responsibility in the prevention of internal displacement, this section will analyse how countries recognise this right and domesticate it into their national instruments. The importance of developing domestic legislation and policies on internal displacement has been supported and promoted by HRC resolutions, ${ }^{10}$ regional legal instruments on IDPs, ${ }^{11}$ and bodies of regional organisations. ${ }^{12}$ This substantial and widespread support for the development of national instruments reflects the crucial role of national responsibility towards IDPs, and how the adoption of national IDP instruments may promote state's primary responsibility towards displaced populations, rather than this responsibility being imposed by an international instrument. Adopting national IDP laws and policies is an important indication of a government's acknowledgement of the existence of the displacement problem and of its responsibility to address it. Critically, such responsibility is especially relevant to states with high numbers of IDPs, which face a greater urgency to address displacement within their territories and adopt relevant IDP laws and policies.

\section{Methodology}

The data collection for analysis that follows entailed identifying a number of national documents that cover the area of displacement and IDPs. These national instruments were analysed in order to examine the extent to which they include prevention measures that can be considered an indication of the recognition of the IDPs' right not to be arbitrarily displaced. Therefore, this right can be identified in each national instrument dealing with different types of prevention of displacement. This is because Principle 6 of the Guiding Principles indicates that the content of the right not to be arbitrarily displaced covers protection from all causes of displacement and includes measures that address the root causes of displacement. The analysis

\footnotetext{
10 The HRC highlighted that national IDP instruments serve as a tool to strengthen the protection of IDPs and to promote measures to prevent displacement.

11 One of the objectives of the Great Lakes Protocol is to provide a legal basis for the domestication of the Guiding Principles into national legislation by Member States and this objective is reiterated in the preamble of the Kampala Convention.

12 The Council of Europe has called upon its member states to use the Guiding Principles as a guidance on the protection of IDPs' rights and incorporate them into their domestic laws and policies. This call for domestic incorporation was repeated on many occasions in the Council of Europe's Parliamentary Assembly Recommendations in the context of the domestic adoption of the GPID and implementation of them by European member states. The Organisation of American States has urged member states to consider the GPID's domestic implementation.
} 
of the national instruments allowed for differentiating between national instruments that implicitly promote the right and those that explicitly promote it. These national instruments can be grouped into three categories:

(i) Prevention of forced displacement/forced eviction (especially in conflict situations)

(ii) Protection from/prohibition of arbitrary displacement (in situations of conflict and natural disasters)

(iii) Early warning systems (especially in cases of natural disasters)

In terms of implicit reference, two categories of national instruments can be identified. The first includes national instruments that fall under the category of 'prevention of forced displacement', and the second category includes national instruments that fall under the category of 'early warning systems'. Even though there is no explicit reference to the right not to be arbitrarily displaced, these two categories can be considered an indicator of a state's recognition of the right not to be arbitrarily displaced because there are certain elements in the national instruments that lead us to understand that the right not to be arbitrarily displaced has been implicitly recognised.

With regard to the first category of national instruments dealing with the 'prevention of forced displacement', these elements are the following: (i) the acknowledgement of a state's primary responsibility to prevent forced displacement and address the root causes of displacement; (ii) the identification of the responsible institution for the protection of IDPs from forced displacement (i.e. Ministry of Refugees and Internally Displaced Persons or Ministry of Displacement); and (iii) the identification of an institutional responsibility to take concrete steps to prevent further displacement. Therefore, if at least one of these elements was evident, the instrument was then classified under the first category. With regard to the second category of 'early warning systems', the element was the inclusion of early warning systems that aim to detect conditions that might lead to displacement of people, with such systems aiming at disaster prevention or conflict prevention.

The third category includes instruments that explicitly endorse the right not to be arbitrarily displaced. Such national IDP instruments specifically use the term 'protection from arbitrary displacement' and explicitly recognise the right not to be arbitrarily displaced. Some of them even use the same wording as the Guiding Principles Principle 6 for IDPs' protection against arbitrary displacement. ${ }^{13}$ It must be noted that all these three categories are not mutually exclusive as it is possible to have a national instrument that covers all three categories.

The analysis that follows discusses how states have developed national legal framework that can be classified under the three categories. A survey of IDP-specific documents between 1998 and 2020 reveals that a total number of 448 instruments, including national laws and policies dealing with IDP-related issues (such as return, rehabilitation, compensation of IDPs and prevention of arbitrary displacement),

${ }^{13}$ The countries that made explicit reference to the Guiding Principles Principle 6 are South Sudan, Iraq, Nigeria, Afghanistan and the Philippines. 
have been adopted or are in the process of adoption. As the focus of this paper is the prevention of IDPs from arbitrary acts of displacement, the analysis focused on how governments address the pre-displacement phase in these IDP-specific national instruments. The analysis showed that 34 countries have addressed the pre-displacement phase, with 62 national instruments that include national strategies, on-going developments, laws and policies. Efforts to prevent and mitigate the adverse effects of displacement varied in all these instruments, depending on a country's exposure to natural disasters, existing tensions or political instability.

\section{Analysis of National Instruments}

The development of national instruments can be understood as the outcome of a longer process that can be observed since the introduction of the GPID in 1998, where state approaches to the inclusion of the provisions on the prevention of arbitrary displacement have evolved gradually. Even though addressing the root causes of displacement was often not at the top of a government's agenda, the inclusion of provisions on prevention of displacement gained attention in the late 90s. This increasing awareness of the need to prevent internal displacement encouraged government authorities to develop a coping mechanism with the causes of displacement. Therefore, promoting the legal recognition of the right not to be arbitrarily displaced, penalizing arbitrary displacement in domestic law, and focusing on policies of disaster/conflict risk reduction and preparedness, comprised the ways to address prevention in national IDP instruments. In this way, governments can take some concrete steps and these steps may allow for the anticipation of displacement. There are also some national IDP legislations that pre-date the year GPID was adopted;14 among them Colombia is the only country that includes 'prevention of forced displacement' clause in its national framework.

In order to provide a better picture on which countries recognise the right not to be arbitrary displaced and how exactly the prevention of displacement is addressed, Table 1 outlines the number of countries in all three categories identified above and the number of national documents that recognise the right not to be arbitrarily displaced.

Three observations can be drawn from Table 1. First, states have placed increasing attention to the recognition of the right not to be arbitrarily displaced. This gradual recognition can be seen with three steps. First, protection from arbitrary displacement is addressed especially in those countries that identify conflict and/or violence as a cause of internal displacement, such as Bosnia-Herzegovina, Colombia, Georgia and Ukraine. In these national instruments, 'prevention of forced eviction of persons in need', 'prevention of the causes that produce forced displacement by violence' and 'protection from forced displacement from his/her permanent place of residence' are commonly used phrases that indirectly refer to the IDPs' right not to be arbitrarily displaced. Second, it is observed that the content of protection from arbitrary displacement has been expanded in national IDP instruments to include causes of natural disasters, in countries including Gambia, 


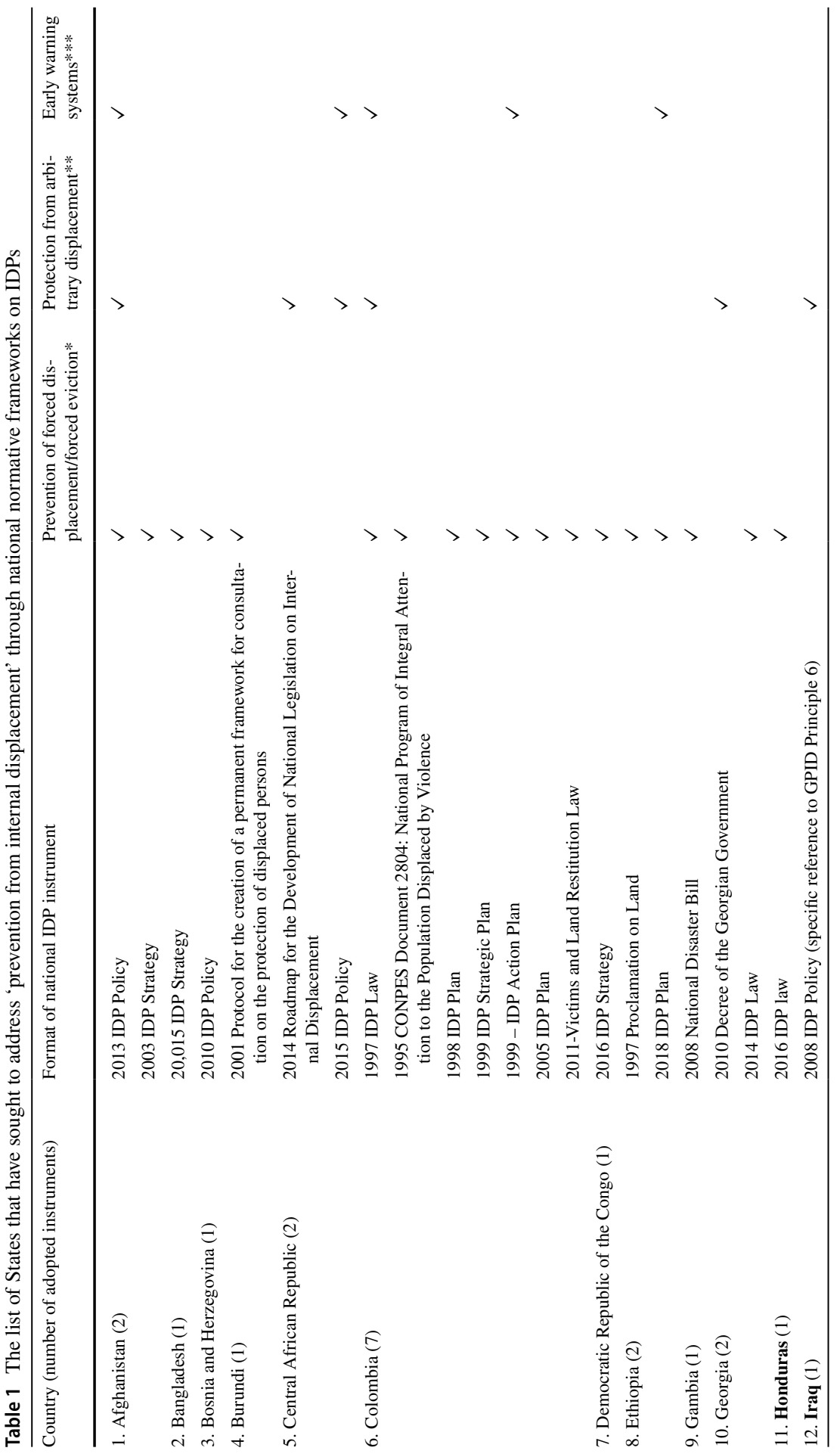




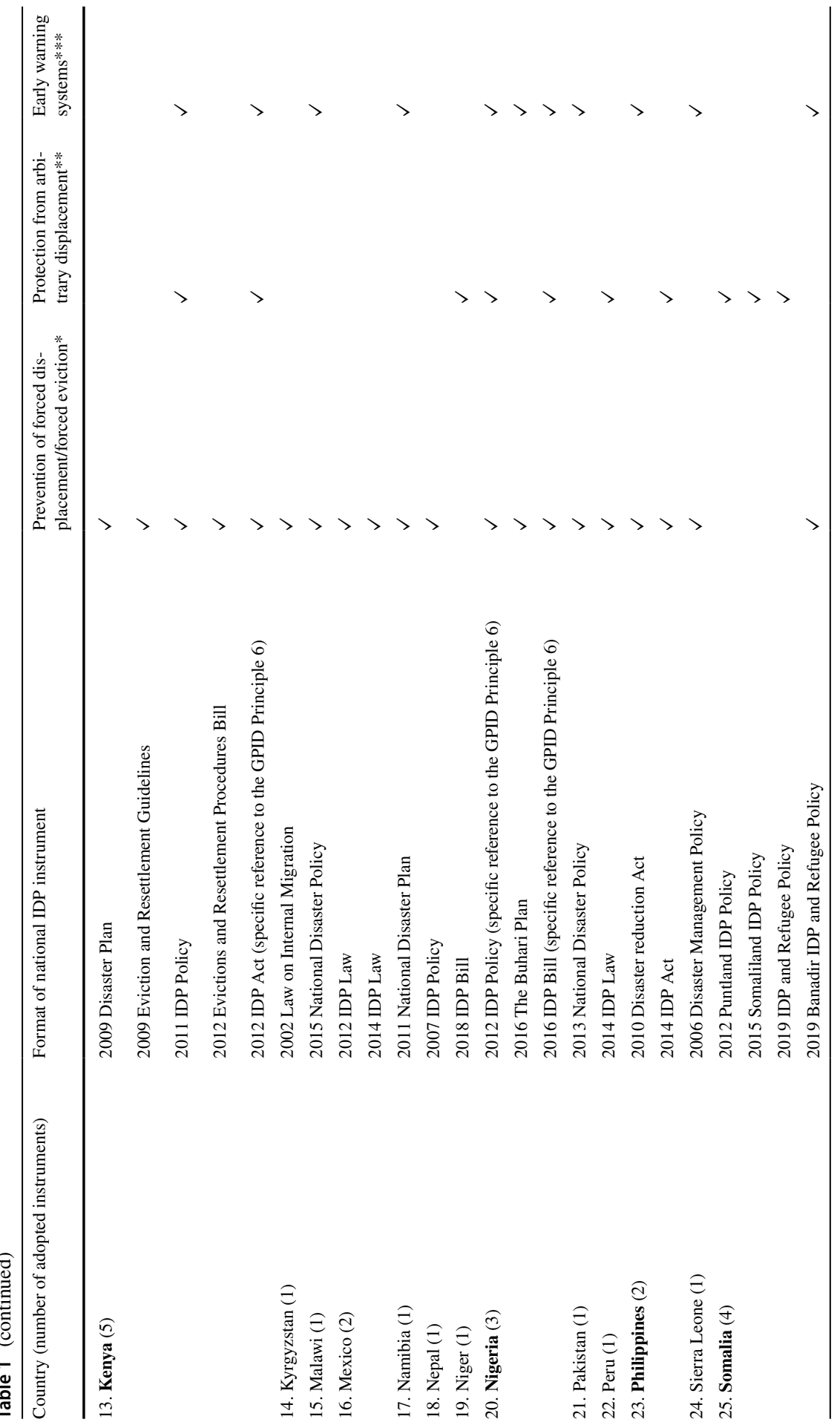




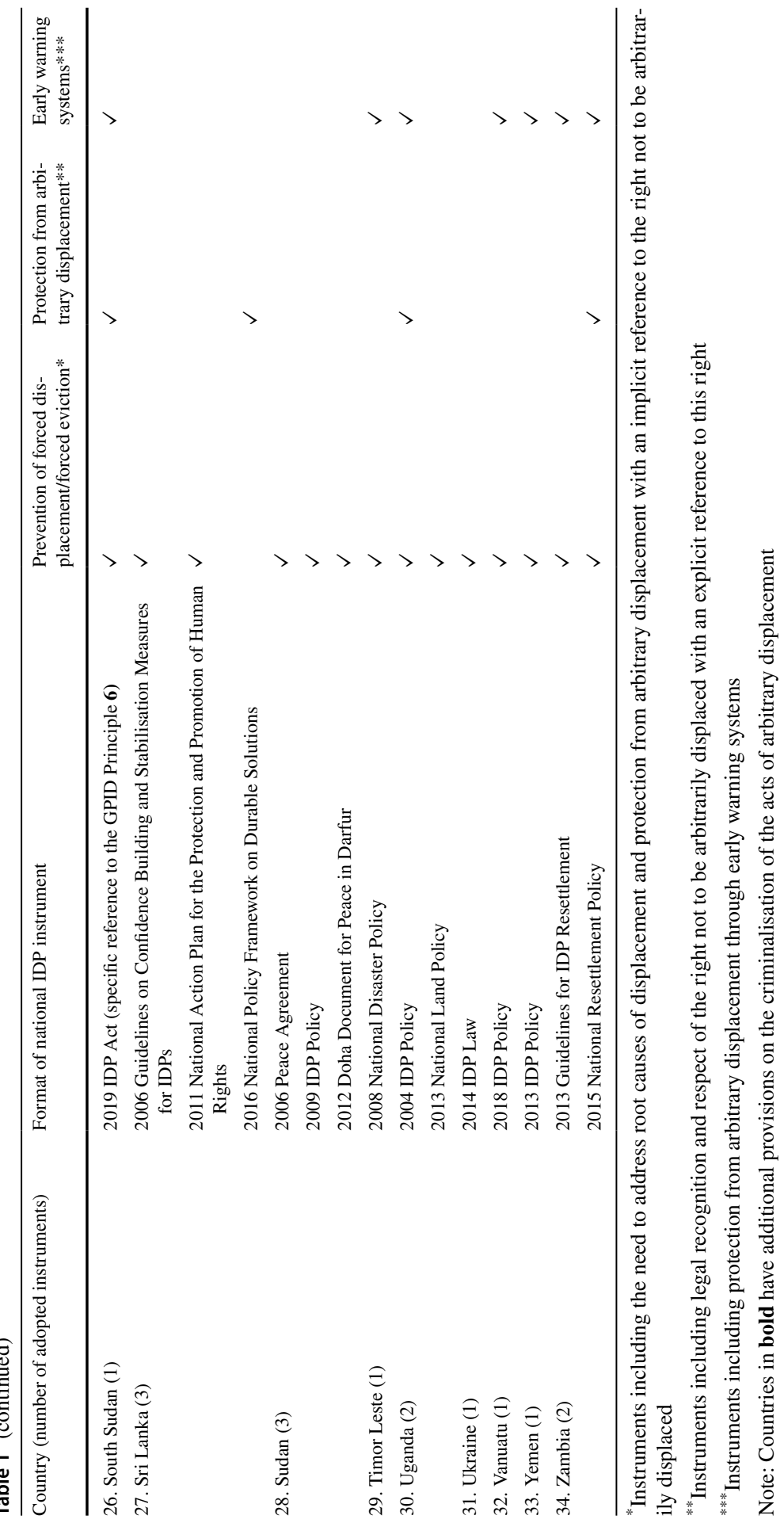


Malawi, Namibia, Sudan, Timor Leste and Kenya, with the phrase 'prevention of displacement caused by natural disasters', 'prevention of disaster or the mitigation of its effects on displaced population' and 'to develop an integrated and effective warning system' because every disaster incident results in internal displacement of affected populations. Finally, the explicit mention to 'right not to be arbitrarily displaced' has started to be used in national instruments, including those of Afghanistan, the Philippines, Iraq, Kenya, South Sudan, Sri Lanka and Somalia.

Second, once states started to make explicit reference to the right not to be arbitrarily displaced, they took two different ways to demonstrate recognition and protection of this right, either using a one-line acknowledgement of the state's responsibility on the 'protection of IDPs from arbitrary eviction or displacement' or with an entire section devoted to the meaning and content of 'arbitrary displacement'. Some examples of the former category are the following. Bangladesh recognises the prohibition of arbitrary displacement of people from their home or place of habitual residence in its national policy (National Strategy on the Management of Disaster and Climate Induced Internal Displacement. 2015). Sri Lanka also recognises the right not to be arbitrarily displaced in its national policy: "every person shall have the right to be protected from forced and/or arbitrary displacement as a result of acts caused by either State itself or non-state actors, or as a result of omission or failure to act' (National Policy Framework on Durable Solutions. 2016. para. 1.1). Here, the state's responsibility to protect its IDPs from acts of arbitrary displacement in situations in which the state is either unwilling or unable to provide protection has been made clear. With regard to the latter category, some countries have opted to recognise the right not to be arbitrarily displaced in a more detailed way. These include the national instruments of Kenya, Somalia, South Sudan, Central African Republic, Afghanistan and Nigeria. These instruments include a definition of arbitrary displacement and affirm that the displaced population has a right not to be arbitrarily displaced. They also provide a non-exhaustive list of acts that are considered arbitrary and identify permissible grounds for displacement, such as military exigencies or compelling and overriding public interests. This approach clearly reflects the content of GPID Principle 6. Indeed, South Sudan, Iraq, Afghanistan and Nigeria have made explicit reference to GPID Principle 6 in their national IDP instruments with an entire section dealing solely with protection from arbitrary displacement.

Third, some countries have taken the right not to be arbitrarily displaced even further by criminalising acts of arbitrary displacement, as in the case of the Philippines, Iraq and Kenya. For instance, the government of Iraq affirmed the criminalisation of acts of displacement, as 'anyone who occupies a house that belongs to a displaced person will be considered as a participant in this displacement' (Prime Minister's Order 101 S. 2008, para. 1). Furthermore, Kenya's national policy includes a section on holding accountable individuals who are responsible for arbitrary displacement as 'the government systematically investigates, prosecutes and punishes crimes under the Penal Code and other relevant laws of Kenya committed or instigated by those responsible for arbitrary displacement' (National Policy on the Prevention of Internal Displacement and the Protection and Assistance to Internally Displaced Persons. 2011, para. 52). Among these countries, the Philippines has the most 
detailed national instrument dealing with the criminalisation of acts of arbitrary displacement, with legislation entitled 'An Act Protecting The Rights of Internally Displaced Persons And Penalizing The Acts of Arbitrary Internal Displacement', which is clearly inspired by Principle 6 of the GPID, as it uses the same wording while describing the impermissible grounds of arbitrary acts of displacement (Rights of Internally Displaced Persons Act. 2014These examples show that there is no longer a question of governments recognising the IDPs' right not to be arbitrarily displaced. What needs to be considered is how this right should be protected, and what is the criminal responsibility in case of violation. The creation of a national policy and law, including the protection from arbitrary displacement and the criminalisation of acts of arbitrary displacement, is a definite positive step forward. ${ }^{14}$

Following from these observations, it is important to consider what the different forms of national IDP instruments tell us on a state's approach to the protection of the right not to be arbitrarily displaced. Existing national instruments vary greatly depending on the country's legal system, culture and particularities of each displacement situation. Naturally, there is a broad variety with respect to their content, format and scope. One of the main reasons for the high number of policies and other formats of instruments, i.e. plan of action and strategy on internal displacement compared to national IDP laws, is that they can be adopted with less formal procedures and therefore often more rapidly than legally binding instruments. If some displacement situations require a more rapid solution, such policies, plan of actions or strategies may be more appropriate to ensure the protection of IDPs. It is also possible that in some internal displacement cases, the law itself may not provide a sufficient basis for addressing the needs of IDPs (Brooking Institution. 2008). For instance, a national policy or plan of action on internal displacement can be complementary to an IDP law by spelling out national and local institutional responsibilities for responding to internal displacement, indicating the roles and responsibilities of different government departments, as well as identifying a mechanism for coordination among them (Brooking Institution. 2005). On the one hand, national IDP laws frequently state general principles, entitlements of IDPs and obligations of the state regarding the cause of displacement. On the other hand, plans of action, strategies and policies are drafted for the purpose of being more specific to the situation of internal displacement by allocating roles and responsibilities of different government departments and identifying actions to address particular challenges in the national response, such as what kind of budget allocations are possible to address such challenges (Brooking Institution. 2008; Schrepfer. 2012). They therefore can be used to elaborate and implement legislation. For instance, as a complementary instrument to its existing national IDP Law (Law of the Republic of Georgia Concerning Internally Displaced People. 1996), Georgia. 2007) was adopted. The strategy calls for review of existing legislation to identify and address obstacles to integration of IDPs; designates the Ministry of Refugees and Accommodations as the leading coordination body with regard to other governmental institutions, international

\footnotetext{
14 Kenya's IDP Policy and the Philippines's IDP Act have yet to enter into force; once entered into force, these instruments will strengthen the effective implementation of the frameworks on the prohibition against arbitrary displacement.
} 
donors, civil society, and IDPs; and calls for the adoption of an action plan to secure adequate resources for the strategy's implementation, allocate functions among those involved, prioritise activities, and set out indicators for monitoring. Another example is Uganda's national policy. As a guide to better implementation of the law that will potentially enter into force later, this policy contains an institutional part outlining the responsibilities of national authorities in line with their obligations, and establishes a mechanism for coordination of response to internal displacement with an entire chapter dedicated to 'Institutional Arrangements, Roles and Responsibilities' (National Policy for Internally Displaced Persons. 2004). These instruments provide a useful example of how to promote effective implementation.

However, one more point needs to be highlighted: the decision for the development of a national instrument including provisions on addressing internal displacement might be influenced by the prevailing political opportunities at the time of the development of the instruments, ${ }^{15}$ i.e. in the election process, as citizens of their own country, the right of IDPs to participate in elections can be used by the government and/or the opposition parties to get the votes of this displaced population by developing a national instrument regarding their protection and assistance. Another example can be found in the post-conflict period. Especially in the ceasefire agreement, governments/parties to the conflict may be imposed to include a clause for the protection and assistance of IDPs by international actors with no plan to followthrough on implementation. In these situations, beyond the strong commitment for the protection of, and assistance to, IDPs on paper, there is the question of whether these policies or laws are actually implemented. Otherwise, this would remain merely the government's strategic rhetorical commitment to the norms embodied in the GPID, with no plan to follow-through on implementation (Orchard. 2019). For instance, the Dayton Peace Agreement (1995) is one of the first ceasefire agreements that is signed with the involvement of international actors such as the Organization for Security and Co-operation in Europe and the United Nations Protection Force to address IDP issues. Annex 7 to the Agreement was designed to be key to the future stability of the region, as it recognised the right of all displaced people to return to their homes of origin, or to receive compensation for property to which, for whatever reason, they could not return. However, after 25 years, durable solutions for IDP resettlement and reintegration are yet to be achieved. The participation of IDPs in the decision-making process (Brooking Institution. 2005) significantly lowers the risk of the resulting instruments being merely symbolic. In the context of protection from arbitrary displacement, while consultation should recognise the basic human right not be displaced on arbitrary grounds, it also makes good sense on a practical level. When affected persons understand why displacement is necessary and are involved in decisions about relocation sites and modalities, they are less likely to resist the move and more likely to offer suggestions to facilitate relocation (Brooking Institution. 2008).

Overall, while there are some limitations to the scope of the laws and policies, developing a national instrument on internal displacement is definitely a positive

\footnotetext{
${ }^{15}$ Schrepher also argues that developing different formats very much influenced by national legal and political traditions.
} 
step forward towards the recognition of IDP rights or the existence of displacement situations within the boundaries of a state, and towards raising the awareness of the need to respond to the plight of IDPs.

\section{Consequences of Internal Displacement and Lack of Resettlement}

The consequences of internal displacement affect not only IDPs, but also the countries and communities that have been IDP hosts. Such consequences, which are often inter-linked, are evident in the areas of health, education, infrastructure, social welfare, housing conditions and climate change (IDMC. 2018). For instance, when people abandon their homes for safety reasons, especially in conflict situations, their physical and mental health is often affected, and consequently, deterioration of health causes degrading conditions in terms of security, housing, education and social welfare. As IDPs get entangled in such adverse conditions, health issues exacerbate through the collapse of social links, especially disruption of family and social ties, the loss of property, such as land and belongings, and the proliferation of grave health issues such as anxiety, depression, and substance abuse (IDMC. 2018). Such conditions entail an extensive scale of human rights violations, including violations of the right to freedom of movement, the right to family life, the right to personal security, the right to property, the rights to food and water, and the right to non-discrimination on grounds of race, ethnicity, religion or political opinion (Prosecutor v Krstić IT-98-33 Trial Judgment 2 August. 2001, para. 523; Mapiripan Massacre v Colombia Judgment of September 15. 2005, para. 111; Ituango Massacres v Colombia Judgment of July 1 2006, para. 207; Kälin et al. 2010). It is worth noting that internal displacement can also comprise a deliberate strategy. Government may promote extractive industries that displace indigenous populations, as in India (Mathur and (Ed.). 2012; Mohanty. 2011) and Colombia (Shultz et al. 2014), or may pursue discriminatory measures to achieve assimilation of populations, as in the Quebec province of Canada (Syed. 2020) and in Myanmar (United Nations General Assemby. 2021). Finally, governments cause forced displacement due to ethnic conflict, with examples including the numbers of IDPs in Bosnia and Herzegovina (Toal \& Dahlman. 2011; Tuathail \& O'Loughlin. 2009), Iraq (United Nations Security Council. 2021) and Rwanda (Norwegian Refugee Council. 2001, IDMC. 2021).

It can overall be argued that a range of different inter-linked and inter-connected factors are integral to internal displacement, and this suggests that internal displacement should be understood as a long-term rather than a short-term challenge, as multiple types of disruption are evident in the host areas. Apart from the exposure to the conflict or violence that triggers internal displacement initially, IDPs face continuous insecurity in the host areas because they are exposed to exploitation due to loss of access to their identity documents and social support networks (Cotroneo. 2017). Armed groups can target men for recruitment, while children, women and older people are especially exposed to insecurity (IDMC Thematic Series. 2018). IDPs also face socio-economic challenges in the host areas, including competing with local workers for jobs, facing higher costs for goods and services, and lack of 
access to housing (Inter-Agency Standing Committee. 2010). Overall, 'anecdotal evidence has repeatedly highlighted the links between displacement and low levels of socioeconomic development, and the need for governments to invest in preventive solutions if they want to ensure inclusive and sustainable development' (IDMC. 2018).

While the return of IDPs to home areas helps promote peace, long-terms solutions are also needed in order to attain security and stability (The United Nations Peacebuilding Support Office. 2012). The process of return and reintegration is crucial for tackling the root cause of conflict and internal displacement (UNHCR Thematic Paper. 2020). Different types of solutions can be identified: (i) return to the place of origin, (ii) local integration in the areas in which IDPs initially take refuge, and (iii) settlement in another part of the country, with the latter two options termed 'resettlement' by the GPID (1998). For such solutions to be considered sustainable, they must advance security and safety, restitution of, or compensation for, lost property, and an environment sustaining the life of former IDPs under normal socio-economic conditions. ${ }^{16}$ The sustainable resettlement of IDPs should also entail integrating IDPs in the decision-making processes of issues such as voluntary return, resettlement and the search of durable solutions (which may include nondiscrimination towards reintegration and addressing any discrimination which may work against hosting communities).

It is important to note that even after return, displaced populations may be facing for prolonged periods the prospect of new and challenging conditions in their home communities. Such conditions demonstrate that internal displacement cannot end immediately after return; ending displacement is instead a long-term process that should ideally lead to the gradual decline of the need for protection and assistance. For example, the process of reclaiming property can be complex, leaving IDPs exposed to lack of shelter, and even when property is secured, this may bring IDPs to new locations where they continue to need humanitarian assistance in order to security employment (IDMC. 2018). Also, the formation of new heterogeneous, mixed communities through the resettlement of IDPs can cause the outbreak of excessive conflict that is fuelled by ethnic divisions and lack of trust across home communities causing the failure of community-building, the failure of reconciliation and, ultimately, the failure of the integration process for IDPs (Pašić. 2015). In the case of the Dayton Peace Agreement in Bosnia and Herzegovina, IDPs only returned to home communities briefly, in order to reclaim and sell their property, and then relocate back to areas where they were the majority (Pašić. 2015). Divisions between ethnic groups also often remain prevalent in certain cases of minority returns as participating and living within the same community does not lead to reconciliation as ethnic groups effectively continue to live within their own separate space. For nationalist political parties, such divisions can be targeted and manipulated in order to cause a new wave of instability. Divisions are also reproduced by the

\footnotetext{
16 Guiding Principles 28-30 spell out the rights of IDPs and responsibilities of competent authorities relating to return, resettlement and reintegration.
} 
process of economic reconstruction, as there is competition between groups over economic resources such as land, as has been evident in cases such as Darfur, Liberia and the Democratic Republic of Congo (Food and Agriculture Organization of The United Nations. 2014).

\section{Conclusion}

This article contributes to understanding the importance of the national level in driving forwards the development of the right not to be arbitrarily displaced, and in this respect, it provides an insight that helps us rethink how national legal framework can address the prevention of internal displacement. National IDP frameworks can initially be shaped by principles of international law but subsequently gain a dynamic of their own. Not all states can necessarily achieve this level of prevention of internal displacement, but we nevertheless saw that a critical mass of states managed to attain a meaningful level of commitment towards the recognition of the right not to be arbitrarily displaced. This national-driven process has not been explored in the IDP literature and raises interesting questions about how IDP rights are established. As far as the right not to be arbitrarily displaced is concerned, this article provides a new perspective on how the national-driven approach can be a more a pragmatic and effective framework for prevention of internal displacement. States take different paths to developing national IDP frameworks and their positive steps might include a wide range of mechanisms of promoting the applicability of this right. Even though countries experience limitations in the applicability of this right, this is not because of the content or the recognition of this right, but due to challenges at the political level, such as the lack of political will or stability. In other words, the recognition of this right is not the question anymore, but what is debated in those countries is the selection of policy-making tools that best achieve the applicability of this right.

\section{Conflict of Interest}

The author declares no competing interests.

\section{Funding Ministry of National Education,Turkey}

Open Access This article is licensed under a Creative Commons Attribution 4.0 International License, which permits use, sharing, adaptation, distribution and reproduction in any medium or format, as long as you give appropriate credit to the original author(s) and the source, provide a link to the Creative Commons licence, and indicate if changes were made. The images or other third party material in this article are included in the article's Creative Commons licence, unless indicated otherwise in a credit line to the material. If material is not included in the article's Creative Commons licence and your intended use is not permitted by statutory regulation or exceeds the permitted use, you will need to obtain permission directly from the copyright holder. To view a copy of this licence, visit http://creativecommons.org/licen ses/by/4.0/. 


\section{References}

Adeola, R. (2016). The right not to be arbitrarily displaced under the United Nations Guiding Principles on Internal Displacement. African Human Rights Law Journal, 16(1), 83-98.

African Union, African Union Convention for the Protection and Assistance of Internally Displaced Persons in Africa (Kampala Convention) (2009).

Annan, K. (1998). Preface in Cohen, R., \& Deng, F. M. (2012). Masses in flight: the global crisis of internal displacement. Brookings Institution Press

Brookings Institution-University of Bern Project on Internal Displacement. (2005). Addressing Internal Displacement: A Framework forNational Responsibility, available at: https://www.refworld.org/ docid/4d357f4f2.html [accessed 28 January 2022]

Brookings Institution-University of Bern Project on Internal Displacement. (2008). Protecting Internally Displaced Persons: A Manualfor Law and Policymakers', University of Bern Project on Internal Displacement, available at: https://www.refworld.org/docid/4900944a2.html [accessed 29 January 2022]

Cohen, R., \& Deng, F. M. (1998). Masses in flight: the global crisis of internal displacement. Brookings Institution Press.

Cohen, R. (2006). Strengthening Protection of IDPs-The UN's Role. Georgetown Journal of International Affairs 7, 101-109.

Commission on Human Rights, Report of the Representative of the Secretary-General, Mr. Francis M. Deng, submitted pursuant to Commission resolution 1997/39 Addendum Guiding Principles on Internal Displacement, E/CN.4/1998/53/Add.2,11 February 1998.

Cotroneo, A. (2017). Specificities and challenges of responding to internal displacement in urban settings. International Review of the Red Cross, 99(904), 283-318.

Eurpoean Court of Human Rights, (2008) Budayeva and Others v Russia, Grand Chamber, Application No.s 15339/02, 21166/02, 20058/02 and 15343/02

European Union Parliamentary Assembly Recommendation 1631 (2003).

European Union Parliamentary Assembly Recommendation 1862 (2009).

Ferris, E. (2008). Assessing the impact of the Principles: An unfinished task. Forced Migration Review GP10, 10-11.

Food and Agriculture Organization of The United Nations (2014). How to deal with people in post displacement- Reintegration: The welcoming capacity approach, available at: http://www.fao.org/3/ mj732e/mj732e.pdf

Forced Migration Review. (2015). Dayton +20: Bosnia and Herzegovina twenty years on from the Dayton Peace Agreement. Issue 50, available at: https://www.fmreview.org/dayton20

Gelazis, N. (2005). The tenth anniversary of the Dayton Accords and afterwards: Reflections on postconflict state- and nation-building. East European Studies.

Georgia. (2007). Decree No. 47 on Approving of the State Strategy for Internally Displaced Persons - Persecuted.

Global Protection Cluster Working Group. (2007). Handbook for the Protection of Internally Displaced Persons, available at: https://www.refworld.org/docid/4790cbc02.html [accessed 28 January 2022]

Global Protection Cluster (GPC). (2010). Handbook for the protection of internally displaced persons, available at: https://www.refworld.org/docid/4790cbc02.html

Guiding Principles on Internal Displacement, submitted pursuant to Commission on Human Rights resolution 1997/39 E/CN.4/1998/53/Add.2 ,11 February 1998, available at: https://www.refworld.org/ docid/3c3da07f7.html [accessed 27 January 2022]

IDMC Thematic Series (2018). The ripple effect: Economic impacts of internal displacement, available at: https://www.internal-displacement.org/sites/default/files/inline-files/201810-literature-revieweconomic-impacts.pdf [accessed 1 October 2021]

IDMC (2018). Multidimensional impacts of internal displacement, available at: 201810-literature-revieweconomic-impacts.pdf (internal-displacement.org) [accessed 15 April 2021]

IDMC (2020). Internal Displacement Index 2020 report, available at: https://www.internal-displacement. org/publications/internal-displacement-index-2020-report [accessed 25 October 2020]

IDMC (2021). Guiding principles on internal displacement, available at: https://www.internal-displaceme nt.org/internal-displacement/guiding-principles-on-internal-displacement [accessed 25 April 2021]

ILO Convention. (1989) No. 169 concerning Indigenous and Tribal Peoples in Independent Countries Indigenous and Tribal Peoples Convention. 
Inter-Agency Standing Committee (2010). IASC Framework on durable solutions for internally displaced persons, The Brookings Institution - University of Bern Project on Internal Displacement, available at: https://www.unhcr.org/50f94cd49.pdf

International Convention on the Suppression and Punishment of the Crime of Apartheid (1976).

International Criminal Court (ICC) (2006). Situation in the Democratic Republic of the Congo ICC01/04, available at: https://www.icc-cpi.int/drc

International Criminal Court (ICC) (2009). The Prosecutor v. Omar Hassan Ahmad Al Bashir ICC-02/05-01/09

International Labour Organization (ILO), Indigenous and Tribal Peoples Convention, No. 169, 27 June 1989, C169, available at: https://www.ilo.org/dyn/normlex/en/f?p=NORMLEXPUB:12100:0::NO:: P12100_ILO_CODE:C169 [accessed 28 January 2022]

International Law Association. (2000). Declaration of international law principles on internally displaced persons.

Ituango Massacres v. Colombia, Judgment of 1 July 2006 (Preliminary Objections, Merits, Reparations and Costs), Inter-American Court of Human Rights

Jacques, M. (2012). Armed conflict and displacement: The protection of refugees and displaced persons under international humanitarian law. Cambridge University Press.

Joseph, S., \& Castan, M. (2013). The international covenant on civil and political rights: cases, materials, and commentary. Oxford University Press

Kälin, W., \& Künzli, J. (2010). The law of international human rights protection. Oxford University Press.

Kälin, W. (2001). How hard is soft law? The guiding principles on internal displacement and the need for a normative framework. Brookings Institution-CUNY Project on Internal Displacement.

Kälin, W. (2005). The guiding principles on internal displacement as international minimum standard and protection tool, UNHCR, Refugee Survey Quarterly, Issue 3.

Kälin, W. (2008a). 'Guiding Principles on Internal Displacement: Annotations', 2nd ed., Studies in Transnational Legal Policy 38 , American Society of International Laws and Brookings Institution, (Annotations), available at: https://www.brookings.edu/wp-content/uploads/2016/06/spring_guidi ng_principles.pdf [accessed 28 January 2022]

Kälin, W. (2008b). Guiding principles on internal displacement: Annotations. Studies in Transnational Legal Policy No. 38. The American Society of International Law Washington, DC, available at: https://www.brookings.edu/wp-content/uploads/2016/06/spring_guiding_principles.pdf

Kälin, W. et al. (2010). Incorporating the guiding principles on internal displacement into domestic law: Issues and challenges, Studies in Transnational Legal Policy No. 41 , The American Society of International Law.

Kofi Annan, Preface, Roberta Cohen and Francis M. Deng, Masses in flight: The global crisis of internal displacement, Brookings Institution, Washington D.C., 1998, p.xix.

Law of the Republic of Georgia Concerning Internally Displaced People, 28 June 1996. Repealed by: the Law of 2014 on Internally Displaced Persons - Persecuted from the Occupied Territories of Georgia

Mapiripán Massacre v. Colombia , Judgment of September 15, 2005 (Merits, Reparations, and Costs), Inter-American Court of Human Rights

Mathur, H. M. (Ed.). (2012). Resettling displaced people: Policy and practice in India. Routledge.

Mohanty, R. (2011). Impact of development project on the displaced tribals: A case study of a development project in Eastern India. Orissa Review.

Morel, M. (2014). The right not to be displaced in international law. Intersentia.

National Policy for Internally Displaced Persons. Uganda. (2004).

National Policy Framework on Durable Solutions. (2016). Sri Lanka, available at: https://www.refworld. org/docid/5a842e5e4.html [accessed 08 January 2020]

National Policy on the Prevention of Internal Displacement and the Protection and Assistance to Internally Displaced Persons. (2011). Kenya. Available at: https://www.refworld.org/docid/5a8412554. html [accessed 08 January 2020]

National Strategy on the Management of Disaster and Climate Induced Internal Displacement. (2015). Bangladesh,available at: https://www.refworld.org/docid/5b2b99f74.html [accessed 08 January 2020]

Norwegian Refugee Council (2001). Profile of Internal Displacement : Rwanda, available at: https:// www.ecoi.net/en/file/local/1412413/dh1354_01689rwa.pdf

Orchard, P. (2019). Protecting the internally displaced: Rhetoric and reality. Routledge.

Organization of American States. (2008). General Assembly Resolution AG/RES 2417 (XXXVIII-O/08). 
Pašić, L. (2015). Political and social consequences of continuing displacement in Bosnia and Herzegovina. Forced Migration Review.

Phuong, C. (2005). The international protection of internally displaced persons. Cambridge University Press.

Prime Minister's Order 101/S (2008). Iraq, available at: https://www.refworld.org/docid/49da18482.html [accessed 08 January 2020]

Prosecutor v Krstić ,IT-98-33, Trial Judgment, 2 August 2001, International Criminal Tribunal for the Former Yugoslavia

Protocol Additional to the Geneva Conventions of 12 August 1949, and Relating to the Protection of Victims of Non-International Armed Conflicts (Protocol II) (1977).

Protocol on the Protection and Assistance to Internally Displaced Persons Great Lakes Protocol on IDPs (2006).

Proukaki K. E. (2018). The right not to be displaced by armed conflict under international law in: Katselli E. ed. Armed conflict and forcible displacement individual rights under international law. Abingdon: Routledge

Rights of Internally Displaced Persons Act, Senate Bill No.1142. (2014). Philippines, available at: https:// www.refworld.org/docid/5b42f5974.html [accessed 08 January 2020]

Rome Statute of the International Criminal Court (last amended 2010)

Schrepfer N. (2012). Addressing internal displacement through national laws and policies: A plea for a promising means of protection. International Journal of Refugee Law. Volume 24, Issue 4.

Shultz, J. M., Ceballos, Á. M. G., Espinel, Z., Oliveros, S. R., Fonseca, M. F., \& Florez, L. J. H. (2014). Internal displacement in Colombia: Fifteen distinguishing features. Disaster Health.

Stavropoulou, M. (1994). The right not to be displaced. The American University Journal of International Law and policy, Vol. 9, No.3.

Syed, I.S. (2020). Hijab, niqab, and the religious symbol debates: Consequences for health and human rights, The International Journal of Human Rights.

The United Nations Peacebuilding Support Office (2012). Peace dividends and beyond: Contributions of administrative and social services to peacebuilding, available at: https://www.un.org/peacebuilding/ sites/www.un.org.peacebuilding/files/documents/peace_dividends.pdf [accessed 03 October 2021]

Toal, G., \& Dahlman, C. T. (2011). Bosnia remade: Ethnic cleansing and its reversal. Oxford University Press.

Tuathail, G. Ó., \& O’Loughlin, J. (2009). After ethnic cleansing: Return outcomes in Bosnia-Herzegovina a decade beyond war. Annals of the Association of American Geographers, 99(5).

UNHCR Thematic Paper (2020). Sustaining peace and forced displacement, available at: https://www. un.org/peacebuilding/sites/www.un.org.peacebuilding/files/unhcr_thematic_paper_on_forced_displ acement_and_sustaining_peace_200117_0.pdf [accessed 02 October 2021]

United Nations Commission on Human Rights. (1998). Guiding principles on internal displacement. UN doc E/CN.4/1998/53/Add.2.

United Nations Commission on Human Rights (2003). U.N. Doc. E/CN.4/2003/86.

United Nations Economic and Social Council (1981). Study on Human rights and massive exoduses E/ CN.4/

United Nations Economic and Social Council (1995). Compilation and analysis of legal norms. E/ CN.4/1996/52/Add.2

United Nations Economic and Social Council. (2005). Principles on housing and property restitution for refugees and displaced people (Pinheiro Principles). UN Doc. E/CN.4/Sub.2/RES/2005/21

United Nations Economic and Social Council. (2005). Explanatory notes on the principles on housing and property restitution for refugees and displaced persons. UN Doc. E/CN.4/Sub.2/2005/Add.1

United Nations General Assembly. (1981). International co-operation to avert new flows of refugees. A/ RES/36/148

United Nations General Assembly. (2010). Protection of and assistance to internally displaced persons. $\mathrm{A} / 65 / 282$.

United Nations General Assembly. (2015). Transforming our world: The 2030 agenda for sustainable development. A/RES/70/1

United Nations General Assembly. (2021). The situation in Myanmar. A/RES/75/287

United Nations Human Rights Committee (HRC) (1999). CCPR General Comment No. 27: Article 12 (Freedom of Movement). CCPR/C/21/Rev.1/Add.9

United Nations Human Rights Committee (HRC) (2007). Resolution 6/32

United Nations Security Council. (2020). Maintenance of international peace and security S/RES/2535 
United Nations Security Council. (2021). The situation concerning Iraq S/RES/2576

Zapater, J. (2010).Prevention of forced displacement: The inconsistencies of a concept. UNHCR Policy Development and Evaluation Service, available at: https://www.unhcr.org/4bbb2a199.pdf

Publisher's Note Springer Nature remains neutral with regard to jurisdictional claims in published maps and institutional affiliations. 